\title{
Environmentally and Economically Feasibility Manufacturing Process of Potassium Nitrate for Small Scale Industries: A Review
}

\author{
Chirag S. Joshi, Manish R. Shukla, Krunal Patel, Jigar S. Joshi, \\ Omprakash Sahu* \\ Department of Chemical Engineering, Kankeshwaridevi Institute of Technology, Jamnagar (GS), India \\ Department of Chemical Engineering, KOIT, Wollo University (SW), Ethiopia \\ *Tel: +251-933520653 \\ *E-mail address: ops0121@gmail.com
}

\begin{abstract}
Potassium Nitrate (PN) is of the basic need of chemical industry. With increase of demand in different production section of fertilizer, pharmaceutical, explosive, food industry etc, potassium nitrate the production becoming non economical to industry. The operating conditions and parameters are the main factors, which responsible for maximised the profits. The main aim of this study is to compared the production potassium nitrate in profitable as well as environmentally suitability way. From the literature different manufacturing process has been summarized for concluding this study.
\end{abstract}

Keywords: Chemical; Discharge; Ions; Salts; Waste

\section{INTRODUCTION}

The earliest known complete purification process for potassium nitrate was outlined in 1270 by the chemist and engineer Hasan al-Rammah of Syria in his book al-Furusiyya wa alManasib al-Harbiyya ('The Book of Military Horsemanship and Ingenious War Devices') [1]. In this book, al-Rammah describes first the purification of barud (crude saltpetre mineral) by boiling it with minimal water and using only the hot solution, then the use of potassium carbonate (in the form of wood ashes) to remove calcium and magnesium by precipitation of their carbonates from this solution, leaving a solution of purified potassium nitrate, which could then be dried [2]. This was used for the manufacture of gunpowder and explosive devices. The terminology used by al-Rammah indicated a Chinese origin for the gunpowder weapons about which he wrote. While potassium nitrate was called "Chinese snow" by Arabs, it was called "Chinese salt" by the Iranians/Persians. A major natural source of potassium nitrate was the deposits crystallizing from cave walls and the accumulations of bat guano in caves [3]. The picture of potassium nitrated is shown in Fig.1. Extraction is accomplished by immersing the guano in water for a day, filtering, and harvesting the crystals in the filtered water. Traditionally, guano was the source used in Laos for the manufacture of gunpowder for Bang Fai rockets [4]. 


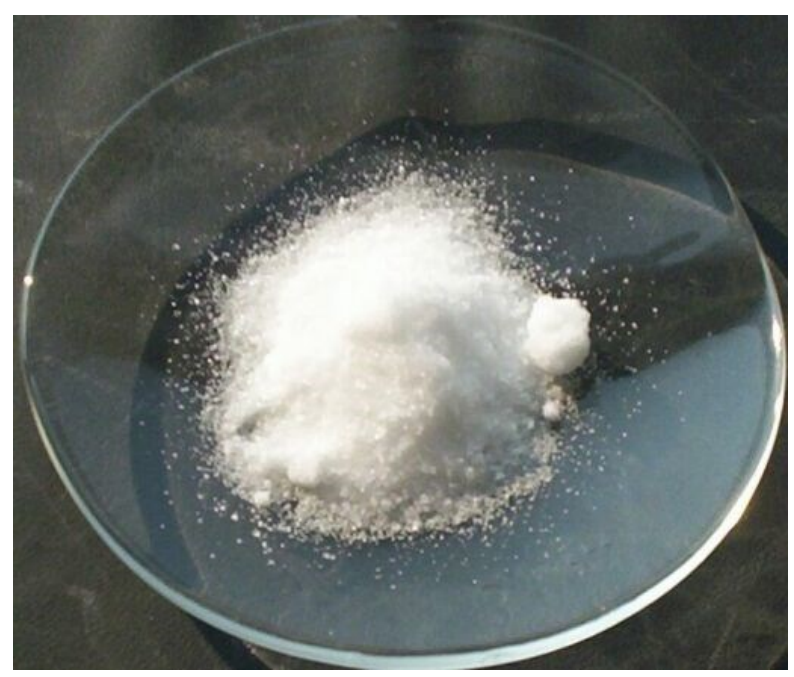

Fig. 1. Potassium Nitrate powder [5].

Potassium nitrates supplied the oxidant and much of the energy for gunpowder in the 19th century, but after 1889, small arms and large artillery increasingly began to depend on cordite, a smokeless powder which required in manufacture large quantities of nitric acid derived from mineral nitrates (either potassium nitrate, or increasingly sodium nitrate), and the basic industrial chemical sulfuric acid. These propellants, like all nitrated explosives (nitroglycerine, TNT, etc.) use both parts of the nitrate ion: the oxygen promotes rapid combustion (thermal energy), and the expansion of the previously solid nitrogen to $\mathrm{N}_{2}$ gas provides kinetic energy [5].

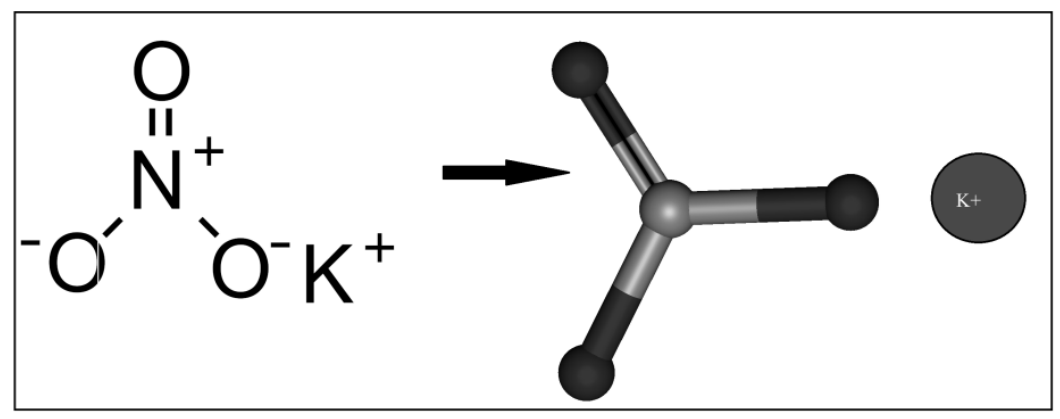

Fig. 2. Molecular structure of potassium Nitrate.

The structure of potassium nitrate has an orthorhombic crystal at room temperature, which transforms to a trigonal system at $129^{\circ} \mathrm{C}$. Upon heating to temperatures between 550 and $790{ }^{\circ} \mathrm{C}$ under an oxygen atmosphere, it loses oxygen and reaches a temperature dependent equilibrium with potassium nitrite. It have moderately soluble in water, but solubility increases with temperature [6]. The aqueous solution is almost neutral, exhibiting $\mathrm{pH} 6.2$ at $14{ }^{\circ} \mathrm{C}$ for a $10 \%$ solution of commercial powder. It is not very hygroscopic, absorbing about $0.03 \%$ water in $80 \%$ relative humidity over 50 days.

It is insoluble in alcohol and is not poisonous; it can react explosively with reducing agents, but it is not explosive on its own. Potassium nitrate is a chemical compound with the formula $\mathrm{KNO}_{3}$. It is an ionic salt of potassium ions $\mathrm{K}^{+}$and nitrate ions $\mathrm{NO}_{3}{ }^{-}$. It occurs as a 
mineral niter and is a natural solid source of nitrogen [7]. Potassium nitrate is one of several nitrogen-containing compounds collectively referred to as saltpeter or saltpetre. The molecular structure of acid nitrate is shown in Fig. 2.

Major uses of potassium nitrate are in fertilizers, rocket propellants and fireworks. It is one of the major constituents of gunpowder (black powder) and has been used since the Middle Ages as a food preservative. Potassium nitrate is also one of the main ingredients in high explosives. In some research production of Mango was increasing $[8,9]$.

It can be also used in chemical industries for maintaining temperature around reactor [10]. As point of view potassium nitrate has more demand on chemical industries all around the world. In open literature different author has been suggested for the production of potassium nitrate [11-13], are not good for environmental and economical point of view by one or another way. So it is required to review of the processes which could be good on economical and environmental point of view for small scale industries. In this regard's an attempted has been made for compared the manufacturing process which are used in small scale industry. The comparisons carried out with air, liquid and gaseous discharge and economical point of view.

\section{MANUFACTURING PROCESS}

In literature different methods has been suggested which are mention below:

1. Reaction between Sodium nitrate and Potassium chloride [11,14-16].

2. Reaction between Ammonium nitrate and Potassium Chloride [17].

3. Reaction between Molten salt (Mixture of Sodium Nitrate ( $54.5 \%$ by wt) and Potassium Nitrate $(44.5 \%$ by wt)) and Potassium Chloride.

4. Reaction between Potassium Chloride and Nitric Acid [18].

5. Production of potassium nitrate by Ion Exchange process. (continuous process) [19].

6. Production of Potassium nitrate by Calcium nitrate and potassium chloride. (Continuous process) [20].

7. Production of potassium nitrate by reaction of aluminium nitrate and potassium chloride. [21].

\section{1. Reaction between Sodium nitrate and Potassium Chloride}

Potassium Nitrate is produced by double decomposition reaction of Sodium Nitrate and Potassium Chloride

$$
\mathrm{NaNO}_{3}(\mathrm{aq})+\mathrm{KCl}(\mathrm{s}) \text {------------ } \mathrm{NaCl}(\mathrm{s})+\mathrm{KNO}_{3}(\mathrm{aq})
$$

A strong, hot solution of $\mathrm{NaNO}_{3}$ is made, and solid $\mathrm{KCl}$ is dumped in to the kettle (Reactor). Upon heating the $\mathrm{KCl}$ crystal change to $\mathrm{NaCl}$ crystals, and the hot potassium nitrate solution is run through the $\mathrm{NaCl}$ crystals at the bottom of the kettle (Reactor). A little water is added to prevent further deposition of $\mathrm{NaCl}$ as the solution is cooled. The good yield of product is result [11,14-16].

\section{2. Reaction between Ammonium nitrate and Potassium chloride}

A method for preparing potassium nitrate and ammonium chloride employing double decomposition reaction comprises the following steps [17]: Dissolving ammonium nitrate and 
potassium chloride in water according to a defined ratio at $110 \mathrm{DEG} \mathrm{C}$, continuously adding potassium chloride and water, heating while stirring to ensure that potassium nitrate is in super saturation state, after stopping heating, cooling the solution in a vacuum cooling crystallizer to 36-40 DEG $\mathrm{C}$ to separate potassium nitrate crystal, placing the potassium nitrate crystal in a centrifugal machine with a filter cloth lining to obtain coarse potassium nitrate, then washing the potassium nitrate with cold water, drying to obtain the finished potassium nitrate.

In addition, adding ammonium nitrate in mother solution I and cleaning solution to adjust solution concentration so that ammonium chloride can reach super saturation state, using a vacuum concentration device to perform negative pressure evaporation, separating and precipitating ammonium chloride by centrifuging and obtaining a solid ammonium chloride product, wherein, when dissolving ammonium nitrate and potassium chloride, the ratio of ammonium ion to chlorine ion is $1: 2$ and when using the centrifugal machine to obtain the coarse potassium nitrate, the separated mother solution is another mother solution I sharing the same saturation point of potassium nitrate and ammonium chloride. The solution of feed liquid circular reaction overcomes the defects of the prior art that the price of potassium nitrate used in reaction is high, the resource of potassium nitrate is in short supply and the cost of devices used in ion-exchange method is high, thus being applicable to the production of potassium nitrate.

\section{3. Reaction between molten salt (Mixture of 54.5\% Sodium Nitrate and 45.5\% Potassium Nitrate) and Potassium chloride}

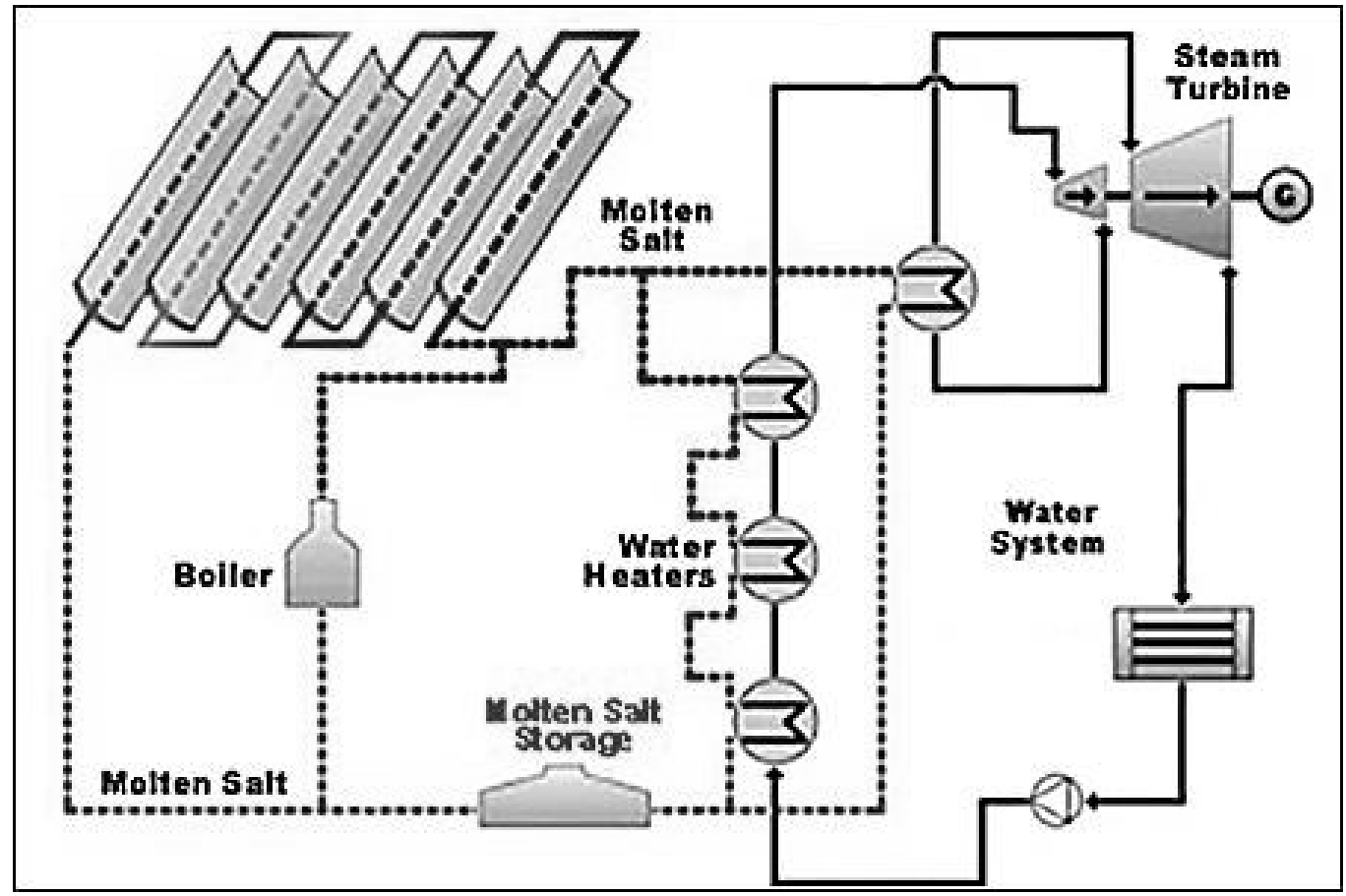

Fig. 3. Reaction molten salt and potassium chloride for production of potassium Nitrate.

Molten salt (Mixture of $54.5 \%$ Sodium nitrite and $45.5 \%$ Potassium Nitrate) is dissolved in the water and potassium chloride is added when the molten salt is dissolved in water completely and after completion of reaction the liquor of potassium nitrate is separated from the sodium chloride by filtration (Because sodium chloride is crystallized first) and then 
the remaining liquor is goes in to crystallizers for crystallization. The flow diagram for reaction molten salt and potassium chloride is shown in Fig. 3.

\section{4. Reaction between the potassium chloride and nitric acid}

The $\mathrm{KCl}$ is dry-screened with the separation of two equal coarse and fine fractions. If prior screening has taken place, the entire coarse $\mathrm{KCl}$ fraction is dissolved. If no such prior screening takes place, approximately $50 \%$ of the $\mathrm{KCl}$ is added at ambient temperature to a dilute nitric acid solution with a concentration of approximately 3 to $10 \%$ by weight and assumed to be between 5 and $10 \%$ of the stoichiometric $\mathrm{HNO}_{3}$. This nitric acid dissolving follows the $\mathrm{HNO}_{3}$ recovery stage by extraction with solvents [18].

The reaction then takes place between the $\mathrm{KCl}$ from the dissolving stage, plus the fines fraction in the case of previous screening, with the nitric acid having a $60 \%$ by weight concentration in an aqueous medium, at ambient temperature and preferably between $15^{\circ}$ and $30^{\circ} \mathrm{C}$., using the reagents in a molar proportion of 0.9 to 1 mole with respect to the initially supplied potassium chloride.

When the reaction is completed, crystallization takes place by cooling the stream to a temperature between $0^{\circ}$ and $-30^{\circ} \mathrm{C}$. in a crystallizer, whose design permits direct contact with a previously cooled petroleum fraction. This is followed by the separation of the potassium nitrate crystals from the resultant brine at an approximate temperature of $20{ }^{\circ} \mathrm{C}$., washing with water and drying, leading to $\mathrm{KNO}_{3}$ as the end product.

The brine obtained in the previous stage is processed by extraction procedures using solvents in order to obtain a brine containing hydrochloric acid with a concentration between 15 and $20 \%$ by weight and which is free from nitrate ions and the $\mathrm{HNO}_{3}$ - containing solvent extract is washed with water to recover the solvent and bring about $\mathrm{HNO}_{3}$ dissolving, which is recalculated for the prior dissolving of $\mathrm{KCl}$, as described hereinbefore.

The organic phase used in this operation is an organic solvent, optionally combined with an inert diluents. Appropriate solvents are ketones with 5 to 10 carbon atoms, polyalkylene glycols, phosphoric, phosphonic and phosphinic acid derivatives and linear or cyclic polyesters. Kerosene, decanes and naphtha can be used as organic diluents.

\section{5. Production of Potassium nitrate by Ion Exchange. (Continuous process)}

The process of production of potassium nitrate by passing a solution of nitric acid through potassium loaded strong cationic exchange resin to produce potassium nitrate. In a preferred embodiment, a fifteen per cent by weight nitric acid solution $\left(15 \%\right.$ wt $\left.\mathrm{HNO}_{3}(\mathrm{aq})\right)$ is passed through a potassium loaded strong cationic exchange resin to produce a solution of about fifteen per cent by weight potassium nitrate $\left(15 \%\right.$ wt $\left.\mathrm{KNO}_{3}(\mathrm{aq})\right)$ and about 0.5 per cent by weight of nitric acid; the solution of potassium nitrate and nitric acid is subsequently neutralized with potassium hydroxide $(\mathrm{KOH})$ to produce a substantially pure aqueous solution of potassium nitrate.

High purity solid potassium nitrate $\left(\mathrm{KNO}_{3}(\mathrm{~s})\right)$ can then be produced by standard crystallization method [19]. The continuous process is shown in Fig.4. 


\section{UPTAKE}
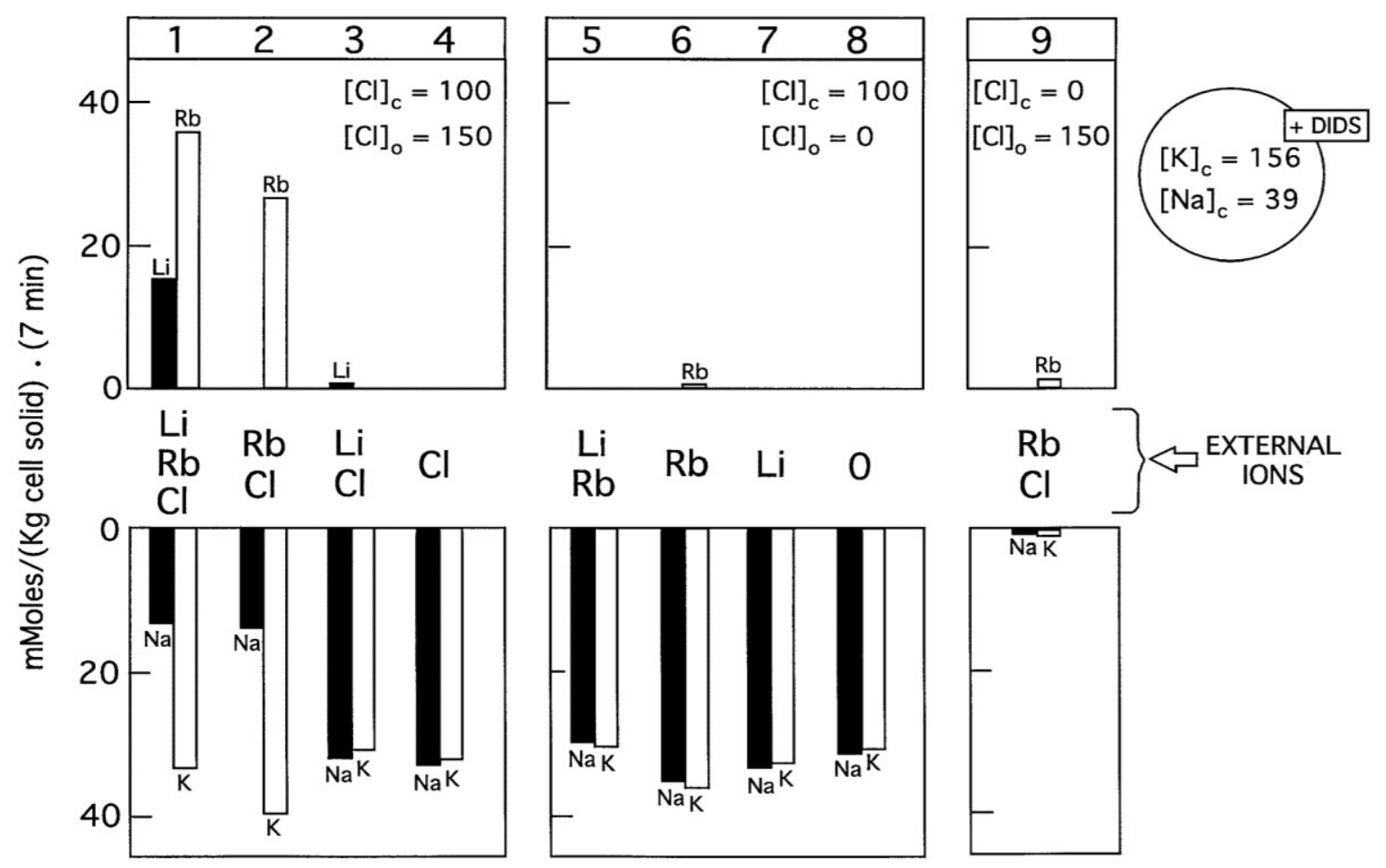

\section{LOSS}

Fig. 4. Production of Potassium nitrate by Ion Exchange.

\section{6. Production of Potassium nitrate by Calcium nitrate and potassium chloride.}

Potassium nitrated is produced by the reaction of potassium chloride with calcium nitrate in aqueous solution by a procedure which eliminates significant loss of nitrate or potassium ions, the process comprising precipitating potassium nitrate from the calcium chloride brine resulting from the reaction, $2 \mathrm{KCl}+\mathrm{Ca}\left(\mathrm{NO}_{3}\right)_{2}=2 \mathrm{KNO}_{3}+\mathrm{CaCl}_{2}$ and recovering the unreacted calcium nitrate from the brine by intimately contacting said brine with an organic solvent which is an extractant for calcium nitrate, which extractant is relatively stable in the presence of the nitrate ion, of low volatility and relatively insoluble in calcium chloride brine.

Following extraction the rich solvent, or ext-ractant, is made lean for reuse and the calcium nitrate recovered for further reaction with potassium chloride by back extraction with water. Following calcium nitrate removal, the un reacted potassium chloride remaining in the brine is recoverable by precipitation upon concentrating the now $\mathrm{Ca}\left(\mathrm{NO}_{3}\right)_{2}$ free brine in known manner. In carrying out the process to obtain potassium nitrate of maximum purity the potassium chloride to calcium nitrate mol ratio, $2 \mathrm{KCl} / \mathrm{Ca}\left(\mathrm{NO}_{3}\right)_{2}$ should be from about 0.7 to 1.0. Preferably the mol ratio is less than stoichiometric, being from about 0.8 to about 0.9 . If less than 0.7 , the maximum amount of potassium nitrate is not precipitated and if the mol ratio is greater than about 1 , then the potassium chloride tends to precipitate [20].

The weight ratio of water to reactants in the initial aqueous solution should be maintained at about 0.7 to about 1.1. The preferred weight ratio is from about 0.8 to about 1 ; this results in a potassium nitrate yield of about 65 of theoretical. The less water used the 
higher the yield of $\mathrm{KNO}_{3}$ in this initial reaction, but potassium chloride also tends to precipitate. Of course, the more water used the lower the yield of potas sium nitrate. Following precipitation of potassium nitrate, a calcium chloride brine remains containing in weight percent, in addition to water, about $65 \%$ calcium chloride $\left(\mathrm{CaCl}_{2}\right.$ about $17 \%$ potassium chloride $(\mathrm{KCl})$ and about $17 \%$ calcium nitrate $\mathrm{Ca}\left(\mathrm{NO}_{3}\right)_{2}$ the latter two compounds representing unreacted portions. Temperature also affects the potassium nitrate yield and while the highest crystallization of $\mathrm{KNO}_{3}$ (about $68 \%$ ) occurs at about $23{ }^{\circ} \mathrm{C}$., at temperatures of about $15 \mathrm{C} . \mathrm{KCl}$ also precipitates; thus, a practical low temperature range of $\mathrm{KNO}_{3}$ crystallization is from about $5 \mathrm{C}$. to about $-10 \mathrm{C}$. At room temperature, e.g., $25^{\circ} \mathrm{C}$., to about $30 \%$ of the potassium nitrate precipitates and the remaining $35 \%$ of the approximately $65 \%$ precipitated takes place at temperatures down around C [20].

After precipitation of the $\mathrm{KNO}_{3}$ by crystallization, the unreacted calcium nitrate and potassium chloride in the brine can be readily recovered for reuse, the unreacted calcium nitrate by the liquid-liquid extraction Procedure of this method and the potassium chloride by known concentration procedures. To recover the unreacted calcium nitrate by liquid-liquid extraction, an organic liquid solvent must be chosen as an extractant in which calcium nitrate is soluble, which is stable in the presence of the nitrate ion, which is of low volatility, and of insignificant solubility in the calcium chloride brine.

We have discovered that tri butyl phosphate satisfies all of these requirements and is an excellent extractant for calcium nitrate which, even when calcium nitrate rich, is quite stable and readily handled under ordinary conditions. It is practically insoluble in calcium chloride brine and is readily made lean for reuse for further extraction by the simple expedient of back extracting with water. Liquid-liquid extraction is ideally suited for continuous potassium nitrate production, the calcium chloride brine being contacted by counter-current flow with the extractant in a solvent (extractant) to feed (brine) ratio in parts by weight of about 3:1 to $6: 1$. It the amount of tributyl phosphate to water is below about 3:1 the number of stages required to extract the calcium nitrate from the brine becomes economically unattractive when used in amounts more than about 6:1, no advantage results and it is economically wasteful. Using 5 to theoretical stages of counter-current flow in the extraction towers, about $99 \%$ of the nitrate value in the brine is recovered in the form of calcium nitrate. To recover the calcium nitrate from the rich extractant for reuse, the nitrate laden solvent is simply back extracted with water in a Weight ratio of about one part water for each four to eight parts rich extractant. About five to six parts extractant for each part water in the back extraction is optimum, and a $13 \%$ by weight concentration of calcium nitrate in water results. This may be readily concentrated to about $23 \%$ and recycled into the system for further reaction with potassium chloride.

The unreacted potassium chloride is recovered from the remaining brine by concentrating the brine and cooling it to about $5 \mathrm{C}$. to $10 \mathrm{C}$. to precipitate the remaining $\mathrm{KCl}$ there from, which is then available for further reaction with calcium nitrate in the production of further potassium nitrate. Because of its innate simplicity the process adapts itself extremely well to continuous production. A suitable arrangement for such production is illustrated in the accompanying drawing, the single figure of which depicts schematically a system suitable for practice of the invention as a continuous process [20].

\section{7. Production of potassium nitrate by reaction of potassium chloride and Aluminium nitrate}

Potassium chloride is introduced under stirring into a hot solution of aluminium nitrate or, vice versa, aluminium nitrate is introduced into a hot solution of potassium chloride. The 
solution is allowed to cool whereupon potassium nitrate separates out. After removal of the potassium nitrate, the mother liquor, which is substantially saturated with potassium chloride and aluminium chloride, is concentrated by evaporation, accompanied by the escape of hydrochloric acid gas, until nitrous gases are being developed. To the liquor, concentrated by evaporation, are added quantities, equivalent to the quantity of hydrochloric acid which escaped, of nitric acid and potassium chloride, the evaporated water being at the same time replaced, so that after the separation of potassium nitrate the original concentration is restored. After cooling of this solution another quantity of potassium nitrate, corresponding to the quantity of potassium chloride added. to the solution, will separate out. In this manner the mother liquor is always returned into the operation so that all losses of potassium and nitrogen are avoided [21].

It was found that it is not necessary to operate at elevated temperature, the conversion taking place also if the nitrate is made to act on potassium chloride in the presence of the corresponding quantity of water in the cold. In this case a mother liquor of the concentration mentioned above is obtained also. Instead of adding nitric acid, one may also add nitrous gases. And also proceed in such manner that after hydrochloric acid gas free from NO has been expelled and the percentage of nitrogen oxides in the escaping gases gradually increases, the solution is heated further, until a substantial part of the chlorine has escaped, whereupon such quantities of potassium chloride, nitric acid and water are added, that after a new quantity of potassium nitrate has been separated out, the original concentration of the liquor is restored, whereupon this liquor is once more evaporated, etc. (25). In this manner the yield of potassium nitrate is greatly increased.

\section{DISCHARGES IN FORM OF SOLID/ LIQUID/ GASEOUS}

In the first process product is potassium nitrate and by-product is sodium chloride (Salt) (3). This sodium chloride could be wash for converting in I.P grade salt. For washing only a washing tank is required which is feasible for small scale industries. This alternate way is good for small scale industries which ignore the dumping of salt (Because dumping of sodium chloride is increases the salinity of soil.). There is no any gaseous discharge during process [8].

Second method: Ammonium chloride is aqueous discharge of process. This Ammonium chloride from process could be crystallized and used as a medicine, fertilizer, food additive and metal work. For the crystallization of Ammonium chloride from the mother liquor of the centrifuge, a separate crystallization unit is required for the separation of Ammonium chloride [17]. The discharge of Ammonium chloride is also a very much hazardous during operation. There is no gaseous discharge during process.

Third method: In this process sodium chloride is produced which is required to convert in to I.P grade salt for making it sellable product. For that sodium chloride is required to wash by some solvents (like water or suitable solvent). So it required some of the special equipments (like washing tanks) in the industry which could be feasible for small scale industries. (Because it ignores the dumping of salt). There is no gaseous discharge during production.

Fourth methods: In this process the hydrochloric acid is obtained during extraction. This hydrochloric acid can be concentrated by simple evaporation process. This could be done by small scale industries. In this process liquid discharge could be reusable after treatment. This 
waste is very less hazardous during handling. There is no any gaseous discharge during process [18]

Fifth method: This is a continuous process and there is no any waste produced during fixed batches of potassium nitrate. But after some period of production, the liquid waste is produced and it is required to discharge from ion exchange cell. There is no any way to reuse or recycle this liquid waste. There is no gaseous discharged during process [19].

Sixth method: No Solid or liquid discharge is produced during process. Brine produced during reaction is recycle after the liquid-liquid extraction. There is no gaseous discharge produced during process [20]

Seventh methods: There is no liquid or solid discharge during process because in this process the mother liquor produced is use as raw material for another fixed quantity of potassium nitrate production batch. But at some extent reused mother liquor is required to discharge. Hydrochloric acid is evolved during the process. [21]

\section{COST ESTIMATION}

The approximately cost estimation was carried out with considering the fixed cost, operating cost, production cost and approximately profits. The cost estimation is giving approximate idea about the small scale potassium nitrate plant establishment.

Here,

Total cost or C.I. = Fixed cost + Operating Cost.

Fixed cost $=$ Cost of machinery and Piping, communication equipments, Pumps etc. Operating Cost $=$ Cost of Raw material, Labour cost, Electricity cost etc.

In fixed cost estimation construction cost and land was not added. The profit was summarized in Table 1:

Table 1. Approximately Cost Estimation for the production of Potassium Nitrate.

\begin{tabular}{|c|c|c|c|c|c|}
\hline Method & $\begin{array}{l}\text { Fixed cost } \\
\quad \text { (Rs.) }\end{array}$ & $\begin{array}{l}\text { Operating } \\
\text { cost (Rs.) }\end{array}$ & Total cost & Product cost & Profit. \\
\hline 1. & $\begin{array}{c}\text { Rs. } \\
12,06,186\end{array}$ & Rs. $6,46,058$ & Rs. 16,02244 & $\begin{array}{c}\text { Rs.91,04130 } \\
\text { (I.P grade } \mathrm{NaCl} \text { ) } \\
\text { Rs. } 100000 \\
\left(\mathrm{KNO}_{3}\right)\end{array}$ & Rs. $85,55,8072$ \\
\hline 2 & $\begin{array}{c}\text { Rs. } \\
2,17,32,900\end{array}$ & $\begin{array}{c}\text { Rs. } \\
6,41,849\end{array}$ & $\begin{array}{c}\text { Rs. } \\
2,23,69,749\end{array}$ & $\begin{array}{c}\text { Rs. } 100000 \\
\text { (Potessium nitrate) } \\
\text { Rs. } 8000 \\
\text { (Ammonium } \\
\text { chloride) } \\
\end{array}$ & Rs.5,33,849 \\
\hline 3 & $\begin{array}{c}\text { Rs. } \\
12,06,186\end{array}$ & $\begin{array}{c}\text { Rs. } \\
10,57,660\end{array}$ & Rs. $22,38,846$ & $\begin{array}{l}\text { Rs. } 91,04130 \\
\text { (I.P grade sodium } \\
\text { chloride) } \\
\text { Rs. } 100000\end{array}$ & Rs. $81,46,470$ \\
\hline
\end{tabular}




\begin{tabular}{|c|c|c|c|c|c|}
\hline & & & & (Potessium nitrate) & \\
\hline 4 & $\begin{array}{c}\text { Rs. } \\
2,19,01,200\end{array}$ & Rs. $6,60,576$ & $\begin{array}{c}\text { Rs. } \\
2,25,36,776\end{array}$ & $\begin{array}{c}\text { Rs. } 100000 \\
\text { (Potessium Nitrate) } \\
\text { Rs. } 22,73,481 \\
\text { (Hydrochloric acid) }\end{array}$ & Rs. $17,12,905$ \\
\hline 5 & Rs. $23,87,372$ & $\begin{array}{c}\text { Rs. } \\
1,09,59,08,1 \\
50 \\
\end{array}$ & $\begin{array}{c}\text { Rs. } \\
1,09,82,70,52 \\
2 \\
\end{array}$ & $\begin{array}{c}\text { Rs. } 100000 \\
\text { (Potessium nitrate) }\end{array}$ & $\begin{array}{c}\text { Rs. - } \\
1,09,81,45,45,5 \\
222\end{array}$ \\
\hline 6 & Rs.32,80,545 & $\begin{array}{c}\text { Rs. } \\
10,79,307\end{array}$ & Rs. $43,59,852$ & $\begin{array}{c}\text { Rs. } 100000 \\
\text { (Potassium nitrate) } \\
\text { Rs. } 6505 \text { (Calcium } \\
\text { chloride) } \\
\end{array}$ & Rs. -972802 \\
\hline 7 & Rs. $20,00,440$ & Rs. $6,25,631$ & Rs. $26,26,071$ & $\begin{array}{c}\text { Rs. } 100000 \\
\text { (Potessium nitrate), } \\
\text { Rs16,826 } \\
\text { (Aluminum } \\
\text { chloride) }\end{array}$ & Rs. $-5,08,805$ \\
\hline
\end{tabular}

Environmentally production involves the design of chemical processes and products that reduce or eliminate the use and generation of hazardous substances in the manufacture and application of the products. By eliminating and reducing waste from chemical processes, the environmentally production aims is to develop a sustainable approach to a cleaner environment that is beneficial to both our society and the economy.

\section{CONCLUSIONS}

All processes are discharges some of liquid or solid discharges which could be converted in reusable products up to some extent. The by- products during the processes are Ammonium chloride, sodium chloride, hydrochloric acid, calcium chloride, and aluminium chloride. Manufacturing process of potassium nitrate by "Reaction between the Ammonium nitrate and potassium chloride" is not economically feasible for the small scale industries. Manufacturing process of potassium nitrate by "Reaction between the sodium nitrate and potassium chloride" is very much feasible economically and environmentally. But in this process the I.P gradation for the sodium chloride is required to maintain. This process is very much nearer to criteria of "economically and environmentally friendly process" for the small scale industries.

The manufacturing process of potassium nitrate by "Reaction of molten salt with potassium chloride" is also a feasible process for the small scale industries. But this process is economically expensive compared to the "Reaction between the sodium nitrate and potassium chloride". One thing can be observes that this process is also feasible process for the criteria of "economically and environmentally feasible processes" for small scale industries. Another manufacturing process of potassium nitrate by "Reaction between potassium chloride and nitric acid" is also a feasible process for the small scale industries. An extractor is required for the separation of hydrochloric acid. And the evaporator is required for the concentrate hydrochloric acid. So this process is economically costly compared to the processes of 
"Reaction between the sodium nitrate and potassium chloride" and "Reaction between the molten salt and potassium chloride". The manufacturing process of potassium nitrate by "Ion exchange" is not feasible economically for small scale industries but it is environmentally very much feasible. The manufacturing processes of potassium nitrate by "Reaction between the Calcium nitrate and potassium chloride" and "Reaction between potassium chloride and Aluminum chloride" are not economically feasible for small scale industries. These processes could be become economically feasible after long period running the large scale plants. These processes also evolve some of the pollutants during process. It can be say that the processes "Reaction between the sodium nitrate and potassium chloride" and "Reaction between the molten salt and potassium chloride" are nearer to the criteria of "environmentally and economically feasible processes for manufacturing potassium nitrate".

\section{References}

[1] Gosnell J. (2005). Efficient Ammonia Production. Hydrogen Conference, Argonne National Laboratory. KBR, USA, 13 October 2005.

[2] Chhoa T. (2006). Shell Clean Coal Energy in Asia-Pacific. Shell, VP Clean Coal Energy Asia- Pacific Shell Gas \& Power, April 10, 2006.

[3] Sukumaran Nair, M.P. (2006). Ammonia industry - today and tomorrow. Hydrocarbon Processing, April 2006, pp. 47-55.

[4] Maurer R., U. Bartsch (2001). Enhanced Plant Design for the Production of Azeotropic Nitric Acid. Heraeus Nitric Acid Conference, Johannesburg, South Africa, November 29-30, 2001.

[5] Williams G., F. Al-Ansari (2007). IFA Benchmarking of Global Energy Efficiency in Ammonia Production. IFA 2007 Technical Committee Meeting - Workshop on Energy Efficiency and CO2 Reduction Prospects in Ammonia Production, 12-14 March 2007, Ho Chi Minh City, Viet Nam.

[6] Flatt A., Flatt J.P., Alexandre R. (1968). Production of potassium nitrate, U. S. Pat. 3361522 A.

[7] Gregirt P. (2001). Production of potassium nitrate", W.O. Pat. 2001077019 A2.

[8] Sarkar R.K., Malik G.C. (2010). Effect of foliar spray of potassium nitrate and calcium nitrate on grasspea (Lathyrus sativus L.) grown in rice fallows.”, Lathyrus Lathyrism Newsletter 2.

[9] Kazemi M., Bull. Env. Pharmacol. Life Science 2 (11) (2013) 03-06.

[10] Nasiri Y., Zehtab-Salmasi S., Nasrullahzadeh S., Najafi N., Ghassemi-Golezani K., Journal of Medicinal Plants Research 4(17) (2010) 1733- 1737.

[11] Norris R.S., Brink J.A. (2012). Chemical Process Insustries”, Mc Graw Hill. Forth Edition, New York.

[12] Haifa Chemical Ltd. (1983).Process for manufacturing of potassium nitrate, U. S. Pat. 4378342 .

[13] Luis S. Portela (1987). Process for obtaining Potessium nitrate from potassium chloride and nitric acid", U.S. Pat. 4668495 A. 
[14] Robertson K., Industrial Engineering and Chemistry Research 34 (2012) 136-145.

[15] Smith and Jacobs, (1960). Production of Chlorine and Alkali metal Nitrates, U. S. Pat. $2,963,345$.

[16] Spealman W., Chemical Engineering 72 (23) (2005) 198-215.

[17] Portela L.S. (1987). Process for obtaining Potassium nitrate from potassium chloride and nitric acid", U.S. Pat. 4668495 A.

[18] Haifa Chemical Ltd. (1983). Process for manufacturing of potassium nitrate", U. S. Pat. 4378342.

[19] Alvaro Abidaud (1992). Continuous production of Potassium nitrate via ion exchange", U. S. Pat. 110578 A.

[20] Sin G.T., Thomas S.W. (1969). Production of potassium nitrate from Calcium nitrate, U. S. Pat. 3433584 A.

[21] Kaselitz O. (1933). Method of producing Potassium nitrate, U. S. Pat. 1925587 A. 